\title{
THE PLASMA VISCOSITY IN PULMONARY TUBERCULOSIS AND RHEUMATIC DISEASES
}

\author{
By JOHN HOUSTON, R. B. WHITTINGTON, I. C. COWAN, AND JOHN HARKNESS \\ (From the Crossley Sanatorium, Frodsham, England, and the Arthritis Clinic of the Royal \\ Infirmary, Sunderland, England)
}

(Received for publication October 1, 1948)

\section{INTRODUCTION}

In 1940 T'ang and Wang (1) measured the erythrocyte sedimentation rate and the plasma viscosity in 176 cases of pulmonary tuberculosis and 56 cases of tuberculosis of other organs. These writers concluded from their data that the plasma viscosity determination may be a more sensitive test for activity of tuberculosis than the sedimentation rate.

Independently, in 1942, Whittington (2) in a study of the mechanics of the erythrocyte sedimentation rate suggested that this procedure might with advantage be replaced by plasma viscosity measurements.

The method was tried on 63 tuberculous patients by Miller and Whittington (3) who found that the plasma viscosity was a more reliable index of the clinical condition than the erythrocyte sedimentation rate. The general findings of the latter paper were confirmed by Houston, Harkness and Whittington (4) and by Harkness, Houston and Whittington (5) after 645 estimations of the plasma viscosity-223 of these were of pulmonary tuberculosis ; 385 were of a variety of diseases and 37 were of normal persons. Although these data indicate that the plasma viscosity is significant in following the course of persons with pulmonary tuberculosis, they show emphatically that the test is non-specific.

For the past 20 years the accepted laboratory method of estimating the general reaction of rheumatic diseases has been the erythrocyte sedimentation rate. From this earlier experience, a trial of the plasma viscosity test in rheumatic diseases also seemed desirable. Cowan and Harkness (6) have reported 320 viscosity estimations made at the Royal Infirmary, Sunderland, in various rheumatic diseases. They found that the viscosity test was much more reliable than the erythrocyte sedimentation rate, and that the measurements of viscosity appeared to be a promising method of investigation in rheumatic diseases.

Woodmansey and Wilson (7) have reported similar findings. While Race (8) believes that in the more severe clinical conditions the plasma viscosity test is superior to the erythrocyte sedimentation rate, he considers that the erythrocyte sedimentation rate may be the more sensitive in detecting the earliest changes in rheumatic disease.

The statistics of the present paper are based on the results obtained up to the end of February 1948, at Sunderland, and to the end of December 1947, at the Crossley Sanatorium (Table I).

So far as we know, the subject of plasma viscosity has not yet been discussed in the American literature: our results are, therefore, presented in order that readers in the United States can form an opinion on what we consider to be the most useful of the physical, non-specific laboratory estimations.

\section{METHODS AND MATERIALS}

\section{Methods}

The type of viscometer that we have used throughout our tests is accurate to about one part in 500, and requires only about $0.7 \mathrm{ml}$. plasma for each test. This is the Whittington viscometer, of which a full specification has already been published (4), together with the details of calibration and operation. Like the original largecapacity Ostwald type of instrument (of which it is a modification) this viscometer requires a waterbath and a stop-watch as additional apparatus.

As anticoagulants, our experience with sodium citrate solution, potassium oxalate, mixed oxalates and heparin leads us to believe that the present choice lies between the $3.8 \%$ aqueous solution of sodium citrate (1 volume solution: 4 volumes blood) and the Heller and Paul mixture (9) of potassium and ammonium oxalates as used for the Wintrobe erythrocyte sedimentation rate.

The range of normality with $3.8 \%$ sodium citrate solution is both absolutely and relatively narrower than with oxalate; thus the differentiation between normal and pathological is easier with the citrate technique. It has the disadvantage that the proportion of citrate solution to plasma depends on the volume of erythrocytes present since a given volume of whole blood is added to a fixed 
TABLE I

Number of plasma viscosily estimations

\begin{tabular}{|c|c|c|c|c|c|c|c|c|c|}
\hline \multirow{2}{*}{ Laboratory } & \multicolumn{4}{|c|}{$3.8 \%$ Sodium Citrate Solution } & \multicolumn{4}{|c|}{ Heller \& Paul's Oxalate Mixture } & \multirow{2}{*}{ Total } \\
\hline & Normal & $\begin{array}{l}\text { Pulmonary } \\
\text { tuberculosis }\end{array}$ & Other & Total & Normal & $\begin{array}{c}\text { Rheumatic } \\
\text { disease }\end{array}$ & Other & Total & \\
\hline Crossley Sanatorium, Frodsham & 14 & 499 & - & 513 & - & 一 & - & - & 513 \\
\hline Royal Asylum, Montrose & $19 *$ & $134^{*}$ & $268^{*}$ & $421^{*}$ & 9* & - & $255^{*}$ & $264^{*}$ & $685^{*}$ \\
\hline Royal Infirmary, Sunderland & $4 \dagger$ & 23 & $37+$ & $64 \dagger$ & $47 \dagger$ & 750 & $169 \dagger$ & $966 t$ & $1,030 \dagger$ \\
\hline Total & 37 & 656 & 305 & $998 *+$ & 56 & 750 & 424 & $1,230 * t$ & $2,228^{*} \dagger$ \\
\hline
\end{tabular}

* 264 tests were performed using both Sodium Citrate and Mixed Oxalates.

$\dagger 27$ tests were performed using both Sodium Citrate and Mixed Oxalates.

volume of citrate solution. It is therefore necessary to make an accurate hematocrit estimation followed by an empirical correction to the observed plasma viscosity, so as to allow for the proportion of citrate solution diluting the plasma in a given case.

The oxalate results are satisfactory for most clinical purposes. As the volume of blood to be added to the prepared bottle is not critical, it is certainly the method of choice where the collection of blood is undertaken in imperfect conditions, such as in a busy out-patient department. Also, it is convenient to estimate the plasma viscosity on a portion of a sample of blood removed for other hematological investigations.

When examining such colloidal solutions as plasma, serum, etc., the "viscosity" value depends on the dimensions of the particular individual viscometer. The differences between two viscometers with the same plasma may be considerable. It is essential therefore to standardize the viscometers to a common standard. The methods of standardization have been discussed elsewhere (4, 10).

Quarter-ounce $(7 \mathrm{ml}$.) capped bottles are prepared for $5 \mathrm{ml}$. of blood by evaporating in an incubator $0.2 \mathrm{ml}$. of an aqueous solution containing $2 \%$ potassium oxalate and $3 \%$ ammonium oxalate. Five $\mathrm{ml}$. ( $\pm 0.5 \mathrm{ml}$.) of venous blood, drawn with minimal stasis, is added. The contents are mixed by gentle rocking to avoid the formation of froth. In the laboratory the blood is centrifuged to separate the plasma. One $\mathrm{ml}$. of the plasma is pipetted into a small evaporating dish, the viscometer is filled, and the viscosity is estimated as detailed previously (4). While it is preferable to complete the estimation as soon as possible, serial testing has shown that delay of as much as five days in some instances has not altered the viscosity results.

When sodium citrate is used as the anticoagulant, $2 \mathrm{ml}$. of a $3.8 \%$ aqueous solution is pipetted into a $10-\mathrm{ml}$. volumetric flask or a centrifuge tube graduated at $10 \mathrm{ml}$. Venous blood is added exactly to the mark and gently mixed. A sample is removed for hematocrit estimation. The remainder is treated as for the oxalate blood above. An empirical correction has to be applied to this viscosity to make allowance for the variation in the plasma-citrate mixture due to anemia. A nomogram for this correction has been published (4).

On the basis of the complicated inter-relationship of the citrate plasma viscosity to the maximum citrate erythrocyte sedimentation rate the viscosity range has been divided into 11 zones. These zones are of special interest with reference to pleural effusions. The limits of the zones are in Table II.

\section{Patient Material}

(a) Tuberculous patients: Clinical grouping of the patients is based on a recent Ministry of Health circular (11) which can be briefly summarized as follows:

A-category: patients in whom tubercle bacilli have never been discovered.

B-category: patients in whom tubercle bacilli have been demonstrated at some time.

Each category is subdivided as follows:

Group 1. Slight or no constitutional disturbance: physical signs and radiological findings of very limited extent: no complications (tuberculous or other) of prognostic gravity.

TABLE II

Division of citrate plasma viscosity range into zones

\begin{tabular}{c|c|c|c|c|c|c|c|c|c|c|c|c}
\hline \hline $\begin{array}{c}\text { Zone } \\
\text { Number }\end{array}$ & 1 & 2 & 3 & 4 & 5 & 6 & 7 & 8 & 9 & 10 & 11 \\
\hline Range & $\begin{array}{l}1.400 \\
1.515\end{array}$ & $\begin{array}{l}1.515 \\
1.558\end{array}$ & $\begin{array}{c}1.558 \\
1.585\end{array}$ & $\begin{array}{c}1.585 \\
1.671\end{array}$ & $\begin{array}{c}1.671 \\
1.698\end{array}$ & $\begin{array}{c}1.698 \\
1.762\end{array}$ & $\begin{array}{c}1.762 \\
1.832\end{array}$ & $\begin{array}{c}1.832 \\
1.865\end{array}$ & $\begin{array}{c}1.865 \\
1.963\end{array}$ & $\begin{array}{c}1.963 \\
2.038\end{array}$ & $\begin{array}{c}2.038 \\
\text { and over }\end{array}$ \\
\hline
\end{tabular}


TABLE III

The plasma viscosity in rheumatic conditions

\begin{tabular}{|c|c|c|c|c|c|c|}
\hline \multirow{2}{*}{ Condition } & \multirow{2}{*}{$\begin{array}{l}\text { Number } \\
\text { of } \\
\text { tests }\end{array}$} & \multicolumn{2}{|c|}{ Plasma viscosity } & \multirow{2}{*}{$\begin{array}{l}\text { Average } \\
\text { packed } \\
\text { cell } \\
\text { volume }\end{array}$} & \multirow{2}{*}{$\begin{array}{l}\text { Average } \\
\text { Wintrobe } \\
\text { E.S.R. }\end{array}$} & \multirow{2}{*}{$\begin{array}{c}\text { Average } \\
\text { total } \\
\text { plasma } \\
\text { protein }\end{array}$} \\
\hline & & Usual range & $\begin{array}{l}\text { Average } \\
\text { of series }\end{array}$ & & & \\
\hline Normal & $\begin{array}{l}56 \\
(43)^{*}\end{array}$ & $\begin{array}{c}1.700-1.950 \\
(1.700-1.950)\end{array}$ & $\begin{array}{l}1.835 \\
(1.853)\end{array}$ & $\begin{array}{l}\text { per cent } \\
44.6 \\
(42.9)\end{array}$ & $\begin{array}{l}m m . / h r . \\
\text { - }\end{array}$ & $\begin{array}{l}\text { 8. per cent } \\
7.12 \\
(7.15)\end{array}$ \\
\hline $\begin{array}{l}\text { Rheumatic fever } \\
\text { Acute } \\
\text { Chronic }\end{array}$ & $\begin{array}{l}16 \\
11\end{array}$ & $\begin{array}{l}2.250-2.900 \\
2.025-2.250\end{array}$ & $\begin{array}{l}2.449 \\
2.091\end{array}$ & $\begin{array}{l}36.1 \\
40.1\end{array}$ & $\begin{array}{l}45.3 \\
21.0\end{array}$ & $\begin{array}{l}7.80 \\
7.85\end{array}$ \\
\hline $\begin{array}{l}\text { Rheumatoid arthritis } \dagger \\
\quad \text { Residual deformity only }\end{array}$ & $\begin{array}{l}23 \\
(8)\end{array}$ & $\begin{array}{c}1.740-1.990 \\
(1.740-1.990)\end{array}$ & $\begin{array}{l}1.909 \\
(1.909)\end{array}$ & $\begin{array}{c}41.9 \\
(41.8)\end{array}$ & $\begin{array}{l}15.0 \\
(19.8)\end{array}$ & $\begin{array}{c}7.24 \\
(7.40)\end{array}$ \\
\hline Chronic & $\begin{array}{l}387 \\
(154)\end{array}$ & $\begin{array}{l}1.950-2.300 \\
(1.950-2.300)\end{array}$ & $\begin{array}{c}2.119 \\
(2.121)\end{array}$ & $\begin{array}{c}42.2 \\
(42.6)\end{array}$ & $\begin{array}{l}24.7 \\
(25.2)\end{array}$ & $\begin{array}{c}7.77 \\
(7.30)\end{array}$ \\
\hline Subacute & $\begin{array}{c}79 \\
(22)\end{array}$ & $\begin{array}{c}2.300-2.550 \\
(2.300-2.550)\end{array}$ & $\begin{array}{c}2.506 \\
(2.513)\end{array}$ & $\begin{array}{c}41.1 \\
(40.8)\end{array}$ & $\begin{array}{c}34.6 \\
(36.1)\end{array}$ & $\begin{array}{l}8.56 \\
(8.50)\end{array}$ \\
\hline Acute & $\begin{array}{l}29 \\
(16)\end{array}$ & $\begin{array}{c}2.500-3.600 \\
(2.500-3.400)\end{array}$ & $\begin{array}{c}3.002 \\
(2.897)\end{array}$ & $\begin{array}{c}39.9 \\
(38.8)\end{array}$ & $\begin{array}{c}35.9 \\
(38.8)\end{array}$ & $\begin{array}{l}9.50 \\
(9.54)\end{array}$ \\
\hline $\begin{array}{l}\text { Infective polyarthritis (atrophic) } \ddagger \\
\text { Chronic } \\
\text { Subacute }\end{array}$ & $\begin{array}{r}58 \\
8\end{array}$ & $\begin{array}{l}1.850-2.300 \\
2.450-2.700\end{array}$ & $\begin{array}{l}2.067 \\
2.550\end{array}$ & $\begin{array}{l}43.6 \\
38.4\end{array}$ & $\begin{array}{l}20.7 \\
30.4\end{array}$ & $\begin{array}{l}7.64 \\
8.44\end{array}$ \\
\hline Chronic hypertrophic osteo-arthritis $\S$ & $\begin{array}{l}27 \\
(17)\end{array}$ & $\begin{array}{c}1.875-2.075 \\
(1.875-2.075)\end{array}$ & $\begin{array}{c}1.929 \\
(1.921)\end{array}$ & $\begin{array}{c}43.9 \\
(44.1)\end{array}$ & $\begin{array}{l}13.4 \\
(8.5)\end{array}$ & $\begin{array}{c}7.38 \\
(7.31)\end{array}$ \\
\hline Non-articular rheumatism \| & $\begin{array}{c}16 \\
(10)\end{array}$ & $\begin{array}{l}1.725-1.950 \\
(1.725-1.950)\end{array}$ & $\begin{array}{c}1.888 \\
(1.896)\end{array}$ & $\begin{array}{c}45.3 \\
(46.3)\end{array}$ & $\begin{array}{l}7.8 \\
(6.7)\end{array}$ & $\begin{array}{c}7.23 \\
(7.34)\end{array}$ \\
\hline Still's disease & 7 & $2.050-2.850$ & 2.352 & 34.2 & 45.0 & 8.01 \\
\hline Gout & 11 & $1.800-2.300$ & 2.051 & 44.0 & 23.8 & 7.65 \\
\hline Atrophic spondylitis & 14 & $1.750-2.300$ & 1.983 & 44.1 & 13.0 & 7.40 \\
\hline
\end{tabular}

* The figures within the parentheses are the statistics for the first 320 tests in Rheumatic Diseases, as previously published (Cowan and Harkness [6]).

$\dagger$ Rheumatoid arthritis-synonym, Atrophic polyarthritis.

Infective polyarthritis (atrophic) cases of atrophic polyarthritis where there is a definite focus of infection, e.g. in a nasal sinus, which is related to the arthritic condition.

\& Chronic osteo-arthritis - synonym, Hypertrophic, degenerative osteo-arthritis.

If Non-articular rheumatism-synonym, Fibrositis, Bursitis, Panniculitis, Periarthritis, Myalgia, etc.

Group 3. Profound systemic disturbance or constitutional deterioration, and marked impairment of function, either local or general. All cases with grave tuberculous or non-tuberculous complications are placed in this group.

Group 2. All cases which cannot be placed in Group 1 or Group 3.

The Ministry of Health grouping is made on admission and it is not established practice to revise downward any such grouping in the case of a recovering patient. However, an A-category patient would be transferred to the B-category if tubercle bacilli were demonstrated at any time during the course of treatment.

(b) Rheumatic patients: These patients were classified as in Table III under "condition."

\section{RESULTS}

\section{In Tuberculosis}

Figure 1 shows the distribution of average viscosities in 330 tests on 289 individuals (including 37 controls). During the period since our last publication of results for pulmonary tuberculosis (4) we have performed 275 viscosity tests on tuberculous patients. ${ }^{1}$

When interpreting Figure 1, it must be borne in mind that the viscosity values are only averages. If, for example, a sufficient number of B.2 sana-

1 All results in this part are for citrate plasma. 


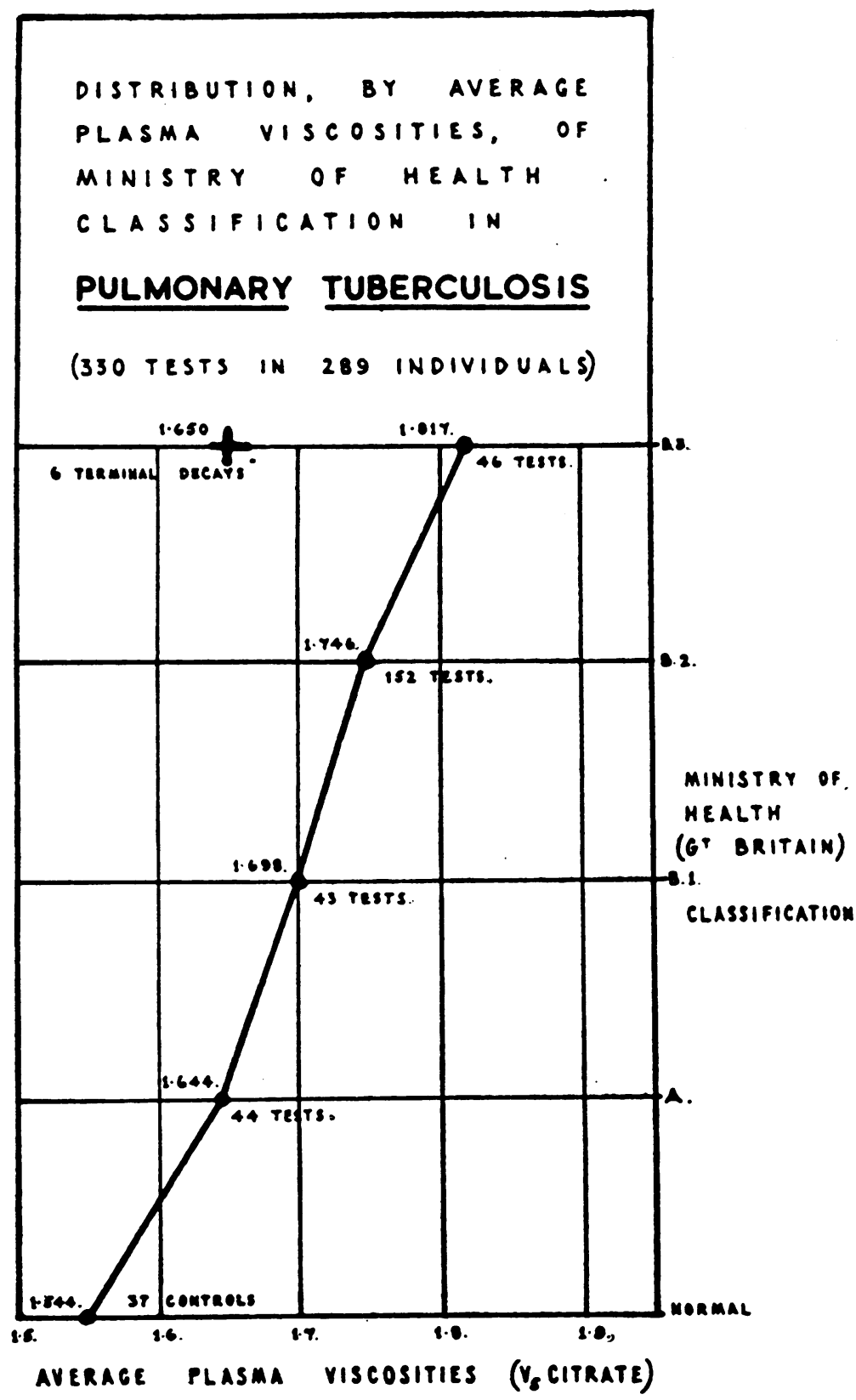

FIG. 1

torium cases be tested, the average of their viscosities will probably be found to be about 1.746 . Nevertheless, the graph shows how, on the whole, the viscosity increases with the spread of disease, since the average viscosities rise fairly steadily from the normals to the most advanced (B.3) category.

The graph does not show, of course, how the viscosities of recovering patients ultimately return to the normal range, but we now have sufficient experience to be able to state definitely that this is so in the patients discharged without physical signs.

Where the disease ends fatally, we have observed a terminal phase in which the final advances of the disease are accompanied by a fall in viscosity towards the normal range. This phenomenon has been termed "terminal decay." 
In Figure 2 we show the distribution according to the citrate plasma viscosity zones of those cases with definite clinical and radiological evidence of the production of clear pleural fluid at the time when the blood was removed for the test. Fortytwo tests on 32 patients are given : $22(52 \%)$ are in viscometric zone $7(1.762$ to 1.832$)$, and 32 $(76 \%)$ are in zones 6 to 8 . These results suggest that zones 6 to 8 form a region in which it is highly probable that exudative cases will lie.

It has been our experience that if a pleural effusion be aspirated while the viscosity is in zone 7,

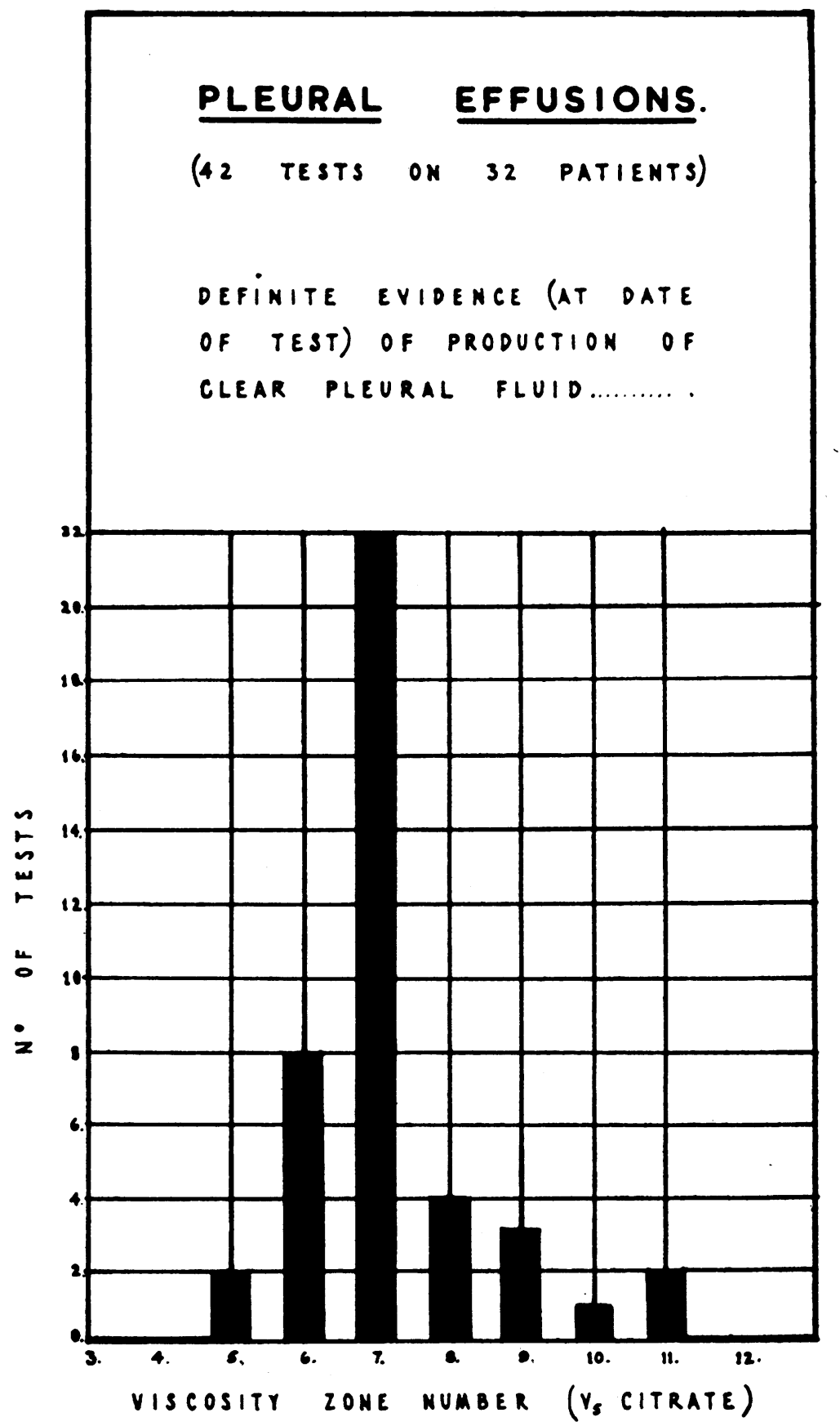

FIG. 2 
the fluid reforms at once. In other cases whose viscosities are either above or below zones 6 to 8 , fluid does not reform after aspiration, although if, later, the viscosity should return to the critical region, the fluid may reform.
No physical explanation of this phenomenon can yet be attempted; but it appears to be of potential importance in the management of pleural effusions, especially as a complication of artificial pneumothorax.

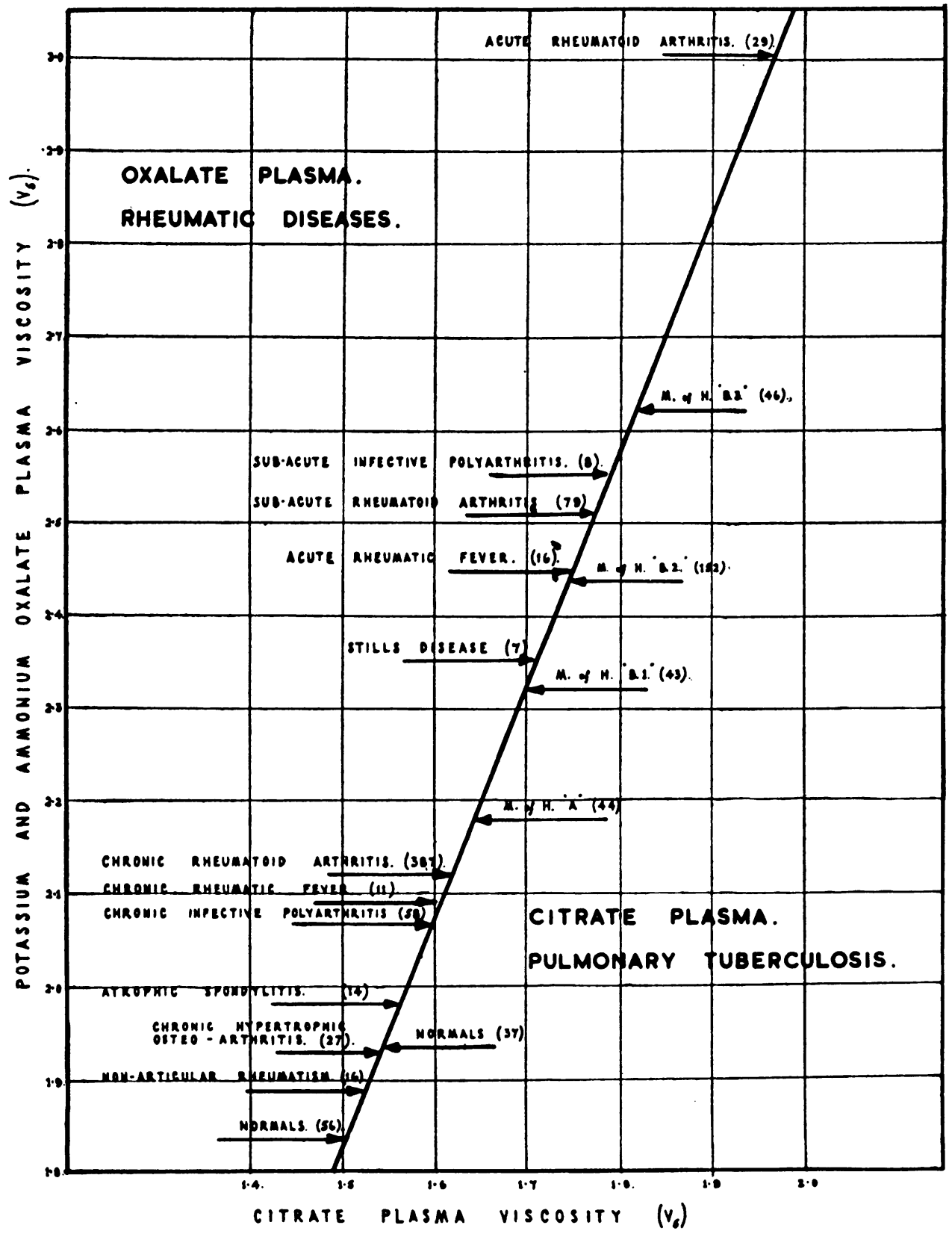

DISTRIBUTION OF AVERAGE VISCOSITIES

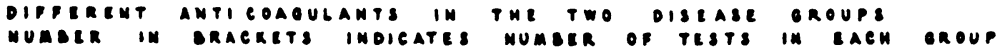

Fig. 3 


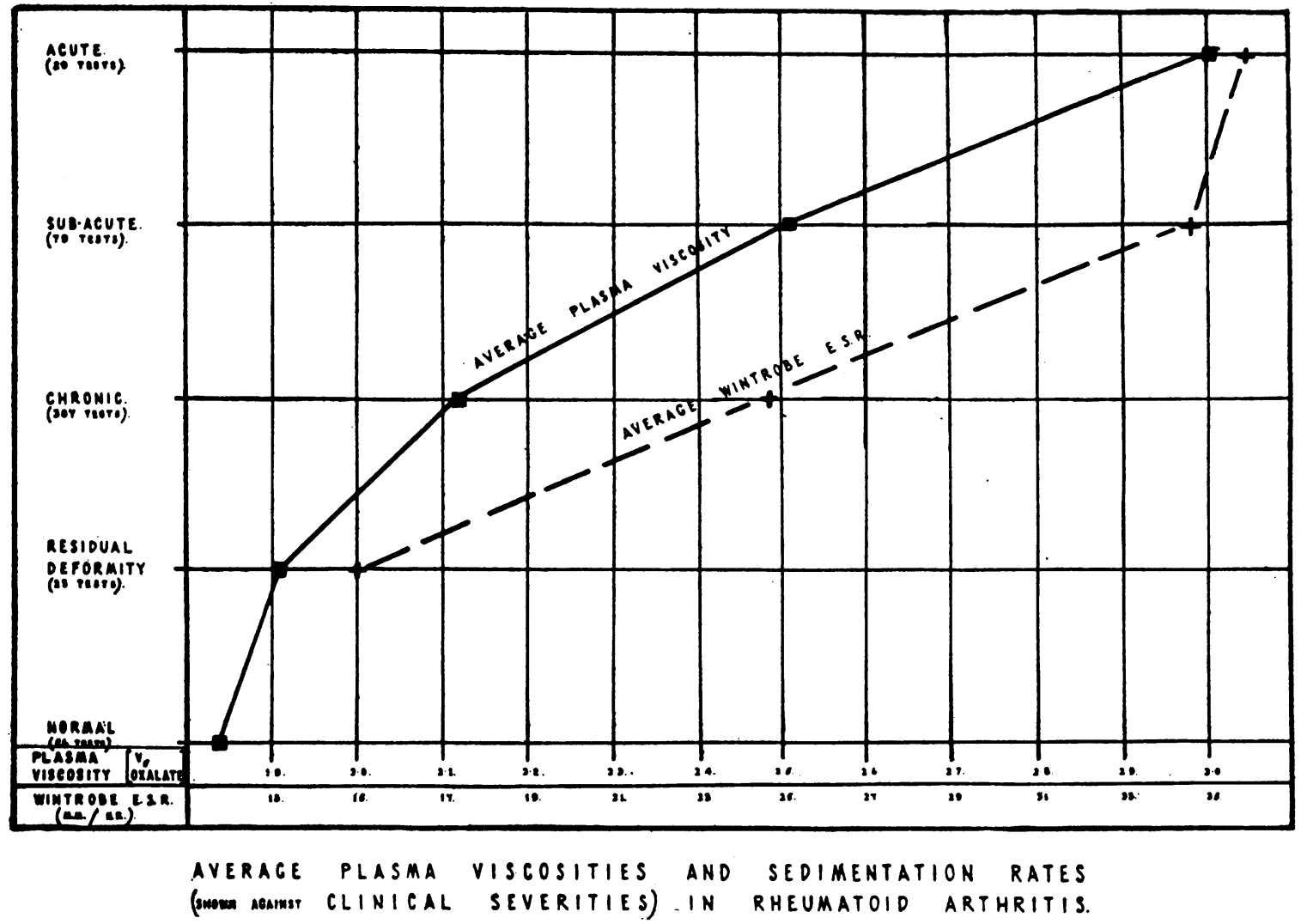

FIG. 4

It is of interest to report that in our only case of tuberculous pericarditis the fluid was formed when the plasma viscosity was in the critical zone 6 to 8 range.

\section{In Rheumatic Disease ${ }^{2}$}

From our experience with more than 750 tests in rheumatic disease, the results can be summarized as follows:

(a) In every case in which the plasma viscosity was raised to an abnormal level (above 1.950) an underlying organic cause was ultimately found.

(b) In rheumatic fever, the plasma viscosity increased as the disease progressed and decreased during recovery. If, during recovery, the nature of the disease process changed from an acute to a chronic type, the change was shown by the cessation of fall or even by a rise in the plasma viscosity; the viscosity was a more sensitive index of this change than the temperature, pulse or erythrocyte sedimentation rate.

\footnotetext{
2 All results in this part are for oxalate plasma.
}

(c) In rheumatoid arthritis the increase in the plasma viscosity was roughly in proportion to the severity of the pathological changes in the locomotor system and to the systemic reaction.

The viscosity values changed with variation in the clinical condition. It required but slight changes clinically to produce significant alterations in the viscosity. With clinical improvement the viscosity values approached those found in normal persons.

In many instances where the plasma viscosity was raised, the erythrocyte sedimentation rate was within normal limits, yet clinically the disease process was active. Conversely, in many cases where residual deformity remained and there was no other indication of systemic upset, the erythrocyte sedimentation rate remained elevated while the viscosity had returned to the normal range.

Figures 3 and 4 present graphically the results given in Table III, indicating the increase of the plasma viscosity with increasing severity of the disease. Figure 4 emphasizes the inability of the 
erythrocyte sedimentation rate to differentiate between subacute and acute conditions.

(d) In cases of non-articular rheumatism where there appears to be no systemic reaction, the plasma viscosity values remain within normal limits.

(e) With chronic hypertrophic osteo-arthritis, there were indications of little or no systemic reaction and this was reflected in the viscosity results.

(f) The findings of the other groups of the rheumatic diseases are given in Table III and Figure 3.

\section{CASE HISTORIES}

\section{Tuberculosis}

Case C. 280, a female, aged 30, was admitted to the Crossley Sanatorium on July 23, 1946, with extensive tuberculous infiltration of the upper third of left lung, with cavitation, and slight infiltration of right outer infraclavicular region.
This patient received routine sanatorium treatment for two months, resulting in improved general condition. Left artificial pneumothorax was induced (Day "minus 38"-chart reference). Following persistent nose-bleeding, the blood-clotting time was estimated and found to be considerably above normal. She was given $60 \mathrm{mgs}$. water-soluble Vitamin $\mathrm{K}$ analogue daily (Day "11"). At routine screening of the chest a minimal effusion in the left costo-phrenic angle was noted (Day "minus 4").

The various laboratory tests carried out, beginning at Day 0, are plotted in Figure 5. Day 81, left internal pneumolysis: three band-adhesions found, two divided and one to the third rib partially divided. On Day 122, the effusion had spontaneously cleared, the cavity remained patent. On Day 214, second internal pneumolysis: as much as possible of the third adhesion was divided. Left effusion developed at once after operation; and 60 ml. of clear fluid were aspirated on Day 221. This left a very small effusion in the costo-phrenic angle, which had cleared spontaneously by Day 269 . The cavity was closed by Day 293 and thereafter clinical progress was uneventful.

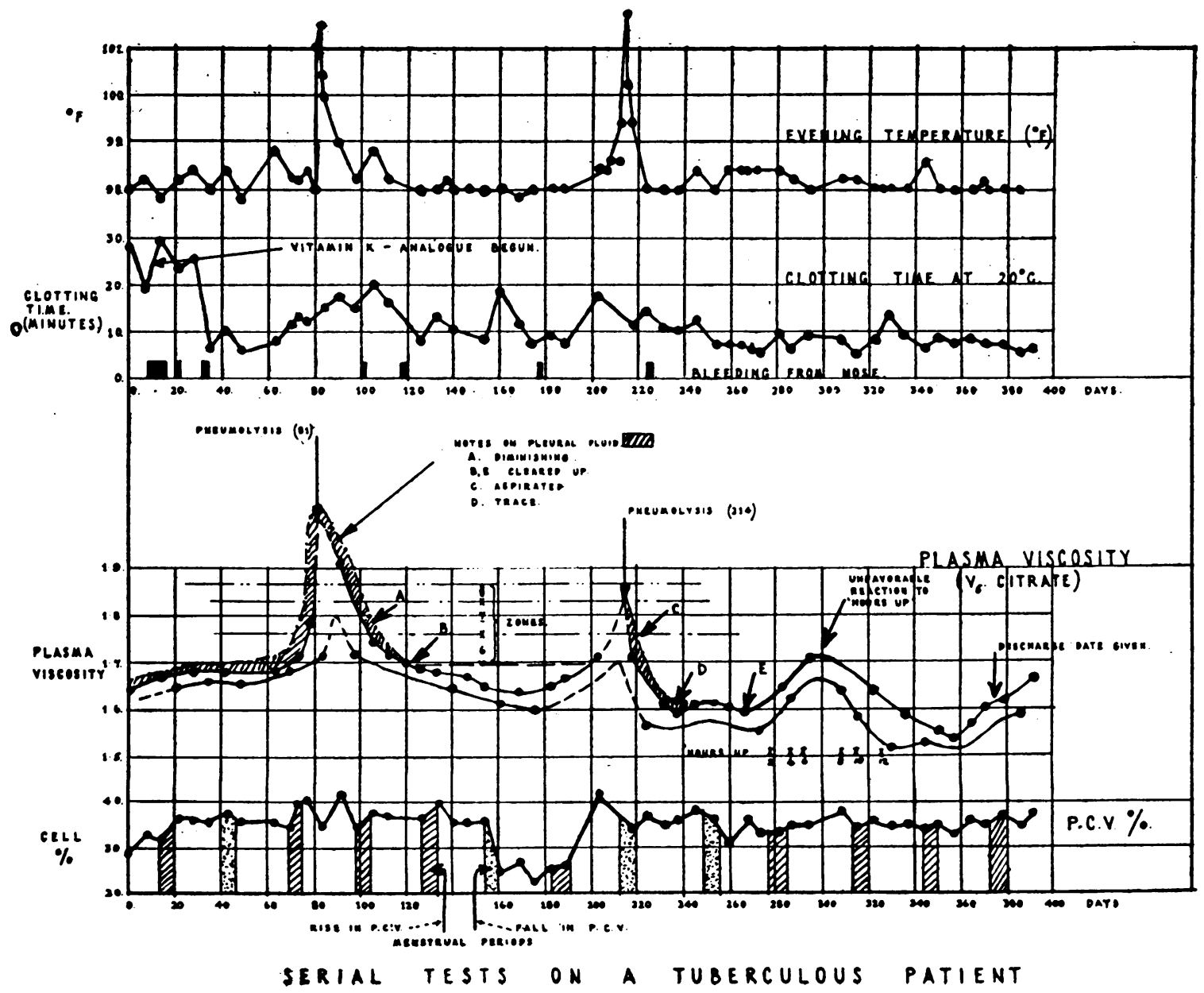

FIG. 5 
This case illustrates several points which we feel are worth discussing. A glance at the chart shows three obvious peaks. All three peaks have definite clinical significance. Peaks 1 and 2 are related to internal pneumolysis, while the third peak is probably a reaction to increasing hours of exercise.

A most interesting feature of peak 1 is that the rise in viscosity was first noticed on Day 73, eight days before the operation, and this rise continued steeply on Day 77, as shown. The patient was informed some time between Days 69 and 73 that adhesion-section would be performed on Day 81 ; and fear of the proposed operation is suggested as the cause of the pre-operational rise. A similar explanation is offered for the pre-operational rise at peak 2.

In support of these observations, we would refer to the findings of Macfarlane and Biggs (12) who have investigated the occurrence of fibrinolysis associated with trauma. They found that in some cases "fear of impending operation" appeared to cause positive results. They also drew attention to parallel observations made by Latner (13) who recorded fibrinolysis in normal subjects during air-raids.

We feel that the rise shown by the last few readings may also have a psychological explanation, since the patient was notified on Day 374, after many months of sanatorium sojourn, of her actual "discharge date."

These phenomena appear to show that the plasma viscosity can be an extremely sensitive index of a patient's condition.

The occurrence of pleural effusion is shown hatched on the viscosity chart. The initial effusion was observed at Day "minus 4," so that we have no record of the viscosity reading at the time of production of fluid. The amount of fluid present as observed radiologically did not appear to increase after Day 0 , despite the fact that the plasma viscosity passed through zones 6 to 8 prior to and following the pneumolysis. Later, however, as the viscosity fell further the effusion cleared spontaneously by Day 122. From this point until the second pneumolysis, the pleural cavity remained dry. Immediately after this operation when the viscosity was within zones 6 to 8 , a second effusion occurred. This was aspirated on Day 221 when, according to the graph, the viscosity was in zone 5; and apart from the small residuum left at aspiration, no further accumulation of fluid took place. By Day 269, the pleural cavity was dry.

\section{Rheumatic Diseases}

1. Acute Rheumatic Fever. Three weeks before admission to the hospital, B. R., a male, aged 42 years, had a sore throat which was followed eight days later by elevated temperature, joint pains and other evidence of a classical attack of acute rheumatic fever. Salicylates were administered in doses sufficient to cause buzzing in the ears, with only partial response. The patient was admitted to the hospital on July $22,1947$.

Sodium salicylate internally and methyl salicylate locally to the painful joints were continued until August
13, 1947, when the sodium salicylate was discontinued (because of toxic symptoms) and replaced by calcium aspirin. The plasma viscosity and the erythrocyte sedimentation rate on August 12, 1947, showed a moderate reaction. The alteration in treatment was followed immediately by an acute recurrence of joint pains, elevation of temperature, sweating, etc., and this worsening was reflected in the increase of viscosity of August 18, 1947, while the erythrocyte sedimentation rate showed an appreciable reduction.

On August 17, 1947, the sodium and methyl salicylate were resumed. On August 23rd, while the patient was receiving large prophylactic doses of penicillin, some decayed teeth were removed. Thereafter improvement was continuous until his discharge on September 11, 1947 (to rest at home). Again the improvement was reflected in the plasma viscosity changes; the erythrocyte sedimentation rate rose inexplicably on August 25th, thereafter also mirroring the clinical improvement.

$\begin{array}{ccccc}\text { Date } & \begin{array}{c}\text { P.C.V. } \\ (\%)\end{array} & \begin{array}{c}\text { Plasma } \\ \text { viscosity }\end{array} & \begin{array}{c}\text { Plasma } \\ \text { protein } \\ (\mathrm{g} . / 100 \mathrm{ml} .)\end{array} & \begin{array}{c}\text { Maximum } \\ \text { citrate } \\ \text { E.S.R. } \\ (\mathrm{mm} . / \mathrm{hr} .)\end{array} \\ 8-12-47 & 41.2 & 2.186 & 7.34 & 55.7 \\ 8-18-47 & 38.5 & 2.228 & 7.13 & 41.2 \\ 8-25-47 & 39.0 & 2.183 & 7.42 & 43.5 \\ 9-4-47 & 41.4 & 2.107 & 7.24 & 35.1 \\ 9-11-47 & 41.3 & 1.997 & 6.91 & 28.8 \\ 1-9-48 & 47.2 & 1.895 & 6.95 & 7.4\end{array}$

When the patient reported three months later to the out-patient department both tests had returned to normal values; there was no clinical indication of activity; there was no evidence of cardiac involvement by the disease.

The plasma viscosity here appears to be a useful index of the pathological processes occurring in the patient.

2. Chronic Rheumatoid Arthritis. O. G., a female, aged 25 years, gave birth to a normal healthy baby in July, 1946. Three months later she began to complain of pain and stiffness of the small joints of the fingers, and then of a tendency towards ulnar deviation of the fingers at the metacarpo-phalangeal joints. Gradually pain and swelling developed in both knees, and there was swelling of the right ankle joint.

There was fusiform swelling of the small joints of the fingers, ulnar deviation at the metacarpo-phalangeal joints, periarticular thickening of both wrists with limitation of dorsiflexion of the right wrist; both knees were hot and swollen, and there was limitation of flexion of the right knee by $20^{\circ}$; the right ankle was "puffy" and painful, although there was full range of movement. General medical examination revealed no focus of infection; urine showed no abnormality; skiagram of chest was negative. Skiagrams of the involved joints showed changes typical of rheumatoid (atrophic) arthritis. The picture was typical of a case of chronic rheumatoid arthritis of some months' duration.

She had been confined to bed at home for eight months prior to admission to hospital on July 2, 1947, when her blood test gave the following results: 


$\begin{array}{ccccc}\text { Date } & \begin{array}{c}\text { P.C.V. } \\ (\%)\end{array} & \begin{array}{c}\text { Plasma } \\ \text { viscosity }\end{array} & \begin{array}{c}\text { Plasma } \\ \text { protein } \\ (\text { g. } / 100 m l .)\end{array} & \begin{array}{c}\text { Wintrobe } \\ \text { E.S.R. } \\ \text { 7mm./1st hr. })\end{array} \\ \text { 7-2-47 } & 41.2 & 2.117 & 7.54 & -\end{array}$

Treatment consisted of rest in bed, active physical therapy, procaine and lactic acid injections (Waugh [14]) to the affected joints, and a course of gold injections (myocrisin). She improved slowly, and by August 20, 1947, she was reported to be capable of standing alone and walking with assistance. The improvement was reflected in her next result:

$\begin{array}{lllll}9-9-47 & 39.6 & 2.038 & 7.45 & -\end{array}$

Treatment was continued. Ferrous sulphate tablets were given to combat the anaemia. Improvement was continuous; and she was discharged on September 30, 1947, walking unassisted.

\section{$\begin{array}{llll}9-30-47 & 40.4 & 1.974 & 7.16\end{array}$}

Three months later, at the beginning of December, she had an attack of influenza. This was followed by a flare-up of all the involved joints. The condition had deteriorated from one of temporary quiescence to one of marked activity, the change being shown also in the laboratory results.
$12-22-47$
43.4
2.326
8.46
28

The patient rested in bed and a further course of physical therapy and myocrisin was given. At the end of the course the pain in the joints had diminished, and weight-bearing was again possible.

$\begin{array}{lllll}3-9-48 & 39.3 & 2.103 & 7.70 & 40\end{array}$

The clinical impression at that time was that the disease condition was being controlled; the fall in the plasma viscosity supported this contention, in spite of the rise in the erythrocyte sedimentation rate. Outpatient treatment was continued. Unfortunately, on June 28th, she reported pain in the right hip which had not been affected previously; a skiagram of this joint showed changes typical of atrophic arthritis. The plasma viscosity reflected this increase in the activity of the disease, in keeping with the involvement of a new joint (a major one). On the other hand, the erythrocyte sedimentation rate decreased.

$$
\begin{array}{lllll}
7-1-48 & 42.9 & 2.213 & 8.35 & 32
\end{array}
$$

3. Chronic Hypertrophic Osteo-arthritis. K. M., a female, aged 50 years, gave a history of pain and stiffness in both knees of six weeks' duration. She had had no other illnesses in her life and no history of injury was given.

There was marked periarticular thickening of both knees, and considerable quadriceps wasting. There was no increased local heat and no synovitis. Her fingers showed Heberden's nodes. Skiagrams of the knees showed the appearance typical of chronic hypertrophic osteo-arthritis. Her laboratory results were:

$\begin{array}{lllll}5-22-47 & 37.9 & 1.871 & 7.45 & 10\end{array}$

Here, as is usually the case in chronic hypertrophic osteo-arthritis, the plasma viscosity was within normal limits.

4. Non-Articular Rheumatism. J. H., a male, aged 34 years, had chronic fibrositis of the upper back almost continuously following rheumatic fever at the age of 17 years. July 17, 1948, after three days in which an acute flare-up made it impossible for him to move his head or shoulders without acute pain, his laboratory findings were:

$\begin{array}{lcccc}\text { Date } & \begin{array}{c}\text { P.C.V. } \\ (\%)\end{array} & \begin{array}{c}\text { Plasma } \\ \text { viscosity }\end{array} & \begin{array}{c}\text { Plasma } \\ \text { protein } \\ (8 . / 100 \mathrm{ml} .)\end{array} & \begin{array}{c}\text { Wintrobe } \\ \text { E.S.R. } \\ \text { (mm./1st hr. })\end{array} \\ 7-17-48 & 45.2 & 1.849 & 7.31 & -\end{array}$

\section{DISCUSSION}

The plasma viscosity test is non-specific. We feel, however, that it is valuable in following the progress of various rheumatic diseases as well as pulmonary tuberculosis. It depends almost entirely on changes in the plasma protein (especially the fibrinogen and globulin fractions), since ultrafiltrate experiments have shown that the viscosity of the ultrafiltrate fluid is practically constant.

If the liver is regarded as the organ which is chiefly responsible for the formation of these plasma proteins then the plasma viscosity is a measure of a change in a liver function, in response to a disease process in the body.

It is not surprising that in pulmonary tuberculosis the systemic reaction and hence the plasma viscosity should parallel the severity of the disease process. In rheumatoid arthritis also the plasma viscosity varies directly with changes in the joints and soft tissues. This emphasizes the general nature of rheumatoid arthritis and the fact that the changes in the joints are only one part of the whole disease process.

In striking contrast are the findings in hypertrophic osteo-arthritis-a localized condition with little systemic reaction-where marked changes can occur in the joints with very little alteration in the plasma viscosity. Similar conclusions can be made for the other rheumatic diseases. In nonarticular rheumatism there is an absence of systemic reaction; and little change in the plasma viscosity. Increased viscosity does occur, however, in such systemic diseases as gout, Still's disease, infective polyarthritis ${ }^{3}$ and atrophic spondylitis.

Since the plasma viscosity is affected only by the plasma proteins, the question arises as to whether it would not be more accurate and informative to

\footnotetext{
${ }^{3}$ See footnote, Table III.
} 
measure the proteins themselves. Consideration of Table III and the individual case histories will show that the total plasma protein is not so sensitive or reliable an indication of the clinical changes as the plasma viscosity. The estimation of the plasma viscosity is technically much simpler and less open to error than the estimation of the protein fractions. Our experience with over 250 parallel estimations of the plasma viscosity and protein fractions has indicated clearly that the viscosity test is by far the more sensitive; the viscosity may have reached definitely abnormal levels when the fractions are still within the usual range of normal values. It is possible to find abnormal protein fractions associated with a normal viscosity, but many of these are cases of terminal decay, to which reference has already been made: in this instance, protein fractionation may be more informative than the viscosity test.

We have not been able to detect any uniform plasma protein pattern associated with plasma viscosities in zones 6 to 8 , where pleural effusions tend to form. In addition to this zone there is another of great clinical significance which cannot be detected readily by protein fractionation. Into the range of 2.025 to 2.175 (oxalate) fall the majority of cases who are suffering from chronic conditions of all types-rheumatic fever, rheumatoid arthritis, infective polyarthritis, syphilis and pyogenic infections. If in the course of a disease two viscosity values, at a few weeks' interval, fall into this zone, it is highly probable that the disease is of a chronic nature; we have noted this happening on several occasions during recovery from acute rheumatic fever when the condition has taken on a chronic nature. The importance of the ability of the test to detect a change from an acute to a chronic process need not be stressed from the aspect of prognosis and treatment.

Although the plasma viscosity test and the erythrocyte sedimentation rate may both reflect changes in the plasma proteins, the results of the two tests may be dissimilar. Careful correlation of the results of these tests with the clinical condition has shown that the plasma viscosity is not only the more reliable but that the erythrocyte sedimentation rate can be definitely misleading. The superiority and the reliability of the plasma viscosity test become very obvious when individual patients have serial examinations during the course of their illnesses. While it must be admitted that in some cases with clinically apparent early disease the erythrocyte sedimentation rate will begin to rise before the plasma viscosity starts to change, there have been instances in which an abnormally high erythrocyte sedimentation rate has been found in an apparently normal person and no cause for this increase has ever been found. In contrast is our experience with over 2500 plasma viscosity tests where in every case of a high viscosity value the cause of this increase was ultimately detected.

\section{CONCLUSIONS}

1. The plasma viscosity has been estimated in 656 tests on cases of pulmonary tuberculosis and in 750 tests on cases of rheumatic disease.

2. The results have been considered generally and some representative cases have been given in detail.

3. The plasma viscosity test is not specific. It depends on changes in the plasma proteins.

4. The plasma viscosity indicates systemic reaction to disease processes.

5. As an indication of the presence of and changes in the systemic reaction the test is sensitive and reliable.

6. The systemic reaction (and hence the plasma viscosity) mirrors the changes in the local lesions in pulmonary tuberculosis, rheumatic fever, and rheumatoid arthritis.

7. The formation of pleural effusions is usually associated with plasma viscosities within a narrow range of values.

8. Chronic disease processes are also associated with a narrow range of viscosity values.

9. The value of the plasma viscosity test to the clinicians treating pulmonary tuberculosis and rheumatic diseases is discussed.

\section{BIBLIOGRAPHY}

1. T'ang, B. H. Y., and Wang, S. H., Clinical application of plasma viscosity determination; description of pipette viscosimeter and report on findings in tuberculosis. Chinese M. J., 1940, 57, 546.

2. Whittington, R. B., Blood sedimentation; study in haemo-mechanics. Proc. Roy. Soc. (B), 1942, 131, 183.

3. Miller, A. K., and Whittington, R. B., Plasmaviscosity in pulmonary tuberculosis. Lancet, 1942. 2, 510 . 
4. Houston, J., Harkness, J., and Whittington, R. B. Plasma viscosity in pulmonary tuberculosis and other diseases. Acta tuberc. Scandinav., 1945, 19, 153.

5. Harkness, J., Houston, J., and Whittington, R. B., Plasma viscosity; clinical test. Brit. M. J., 1946, $1,268$.

6. Cowan, I. C., and Harkness, J., Plasma viscosity in rheumatic diseases. Brit. M. J., 1947, 2, 686.

7. Woodmansey, A., and Wilson, J. V., A method for measuring plasma viscosity and a comparison of plasma viscosity with blood sedimentation rate in rheumatoid arthritis. Ann. Rheum. Dis., 1948, 7, 235.

8. Race, J., Plasma viscosity and suspension stability in chronic rheumatic diseases. Ann. Rheum. Dis., 1948, 7, 239.
9. Heller, V. G., and Paul, H. J., Changes in cell volume produced by varying concentrations of different anticoagulants. J. Lab. \& Clin. Med., 1934, 19, 777.

10. Harkness, J., and Whittington, R. B., On the viscosity of solutions of human albumin and globulin. Biochem. et Biophys. Acta, 1947, 1, 487.

11. Ministry of Health (Great Britain) Appendix to Memorandum. 1947, May. (Revised) 37/T.

12. Macfarlane, R. G., and Biggs, R., Observations on fibrinolysis; spontaneous activity associated with surgical operations, trauma etc. Lancet, 1946, 2,862 .

13. Latner, A. L., Communication to Physiological Society. (1946)

14. Waugh, W. G., Mono-articular osteo-arthritis of hip; treatment by acid injection. Brit. M. J., 1945, 1, 873 . 